\title{
The Effect of Digital Economy and Artificial Intelligence on The Participants of The School Educational Process
}

\section{El efecto de la economía digital y la inteligencia artificial en los participantes del proceso educativo escolar}

\author{
Mikhail V. Vinichenko \\ Russian State Social University, Moscow, Russia. \\ ORCID: https://orcid.org/0000-0003-1973-3485

\section{Marina V. Rybakova} \\ Lomonosov Moscow State University, Moscow, Russia. \\ ORCID: https://orcid.org/0000-0002-7000-8986

\section{Marina V. Vinogradova} \\ Russian State Social University, Moscow, Russia. \\ ORCID: https://orcid.org/0000-0003-3219-9424 \\ Maksim A. Malyshev \\ Lomonosov Moscow State University, Moscow, Russia. \\ ORCID: https://orcid.org/0000-0002-4672-6005

\section{Arseny A. Maksimov} \\ Lomonosov Moscow State University, Moscow, Russia. \\ ORCID: https://orcid.org/0000-0001-7867-250X
}

Received 02-12-20 Revised 03-13-20 Accepted 07-13-20 On line 08-29-20

*Correspondence

Email: m.v.vinichenko@mail.ru
Cite as: 


\section{Summary}

The article examines the nature of the effect of the digital economy and artificial intelligence on the participants of the school educational process. The study deploys a Likert scale questionnaire, focused interview, and IBM SPSS Statistics 22 as the main instruments. The authors determine the status of a teacher in the AI-teacher system and identify the nature of AI's influence on the students and communication within the teacher-student-teacher system. Support is provided for the hypothesis suggesting that the effect of the digital economy and AI on the participants of the school educational process (teachers and students) is complex and controversial and causes the differences in the teachers' positions depending on their age, working experience, and the subject of specialization. The primary advantage of the article is the identification of stable relationships in the teacher-student-teacher system developing with the help of AI. The study indicates the teacher's advantage over AI in teaching technique and social influence, as well as the negative effect of AI on students' health. For the first time, the authors examine the nature of role changes in the AI-teacher system in the context of a global pandemic. The danger of AI replacing teachers with the help of teachers themselves is identified. The acquired results may be used by theorists and practitioners for further development of the foundations of the system of education and human interaction with $\mathrm{AI}$ in the digital economy.

Keywords: Artificial Intelligence; Educational Process; Teacher; Student; Digital Economy.

\section{Resumen}

El artículo examina la naturaleza del efecto de la economía digital y la inteligencia artificial en los participantes del proceso educativo escolar. El estudio despliega un cuestionario a escala Likert, una entrevista focalizada e IBM SPSS Statistics 22 como instrumentos principales. Los autores determinan el estado de un maestro en el sistema AI-maestro e identifican la naturaleza de la influencia de AI en los estudiantes y la comunicación dentro del sistema maestro-estudiante-maestro. Se brinda apoyo a la hipótesis que sugiere que el efecto de la economía digital y la IA en los participantes del proceso educativo escolar (docentes y estudiantes) es complejo y controvertido y provoca diferencias en las posiciones de los docentes según su edad, experiencia laboral, y el tema de especialización. La principal ventaja del artículo es la identificación de relaciones estables en el sistema maestro-alumno-profesor que se desarrolla con la ayuda de AI. El estudio indica la ventaja del profesor sobre la IA en la técnica de enseñanza y la influencia social, así como el efecto negativo de la IA en la salud de los estudiantes. Por primera vez, los autores examinan la naturaleza de los cambios de roles en el sistema AI-profesor en el contexto de una pandemia global. Se identifica el peligro de que la IA reemplace a los maestros con la ayuda de los mismos maestros. Los resultados obtenidos pueden ser utilizados por teóricos y profesionales para un mayor desarrollo de los fundamentos del sistema de educación e interacción humana con la IA en la economía digital.

Palabras clave: Inteligencia artificial; Proceso educativo; Docente; Alumno; Economía digital.

\section{Introduction}

The rapid development of science, society, and the economy transforms modern civilization. Substantial changes occur due to the development of digitalization in various areas of life (Manita et al., 2020; Sukhorukov et al., 2018; Moskaleva et al., 2018). 
The introduction of new technology into learning contributes to the development of human abilities (Tong et al., 2020; Vergara et al., 2020; Kamimura \& Takeuchi, 2019) and human capital (Ossmy et al., 2019; Pomato, 2020). The use of gamification is suggested for improving the quality of education (Shakhovska et al., 2020). The need to create favorable conditions for the education and development of youth (Isoard-Gautheur et al., 2019; Rogach et al., 2016; Vinichenko et al., 2017), especially talented youth, is arising. The search and battle for talented people take place in every stage of human development (Sears, 2003; Effron \& Orth, 2014; Thunnissen \& Buttiens, 2017).

Artificial intelligence is being actively implemented in the social sphere (Abubakar et al., 2019; Zimenkova, Paramonova \& Lobacheva, 2018) and business activity (Alzoubi, Almaliki \& Mirzaei, 2019; Kumar, Kumar, 2019). A range of scientists examines the opportunity of using social creativity to compensate for the loss of human originality (Cha et al., 2020). Studies on the implementation of AI in medical personnel training and improving the effectiveness of the medical industry through image visualization (Lee et al., 2019), developing artificial neural networks (Zhang et al., 2019), and diagnosing diseases (Kurita et al., 2019) are being conducted.

However, the results of the introduction of $\mathrm{AI}$ into human life have not been examined to the fullest extent (Simone \& Andrea, 2020; Barry, 2019). AI is found to be capable of helping humans to model systems (Koch \& Brockmann, 2019), drive cars (Kamal \& Adouane, 2019), treat diseases (Das, Sanyal \& Datta, 2019), and teach innovations (Abassi \& Boukhris, 2018).

AI can also produce negative effects on working conditions (Fujimura, 2019), oust people from the labor market, "taking away" their jobs (Shi, 2019), and deceive society by spreading fake news (Zanotti, 2018). AI is also capable of highlighting and exacerbating the worst qualities of a person (Burrell, 2019) and making decisions for them ensuring the entire management process. Human exposure to AI has been found to be leading to the manifestation of mental health problems (Kalmady et al., 2019).

All the above-mentioned effects of AI are reflected in the educational process and its participants. The modern education system does not possess enough resources to compensate for the issues arising as a result of the digital transformations of society (Rogach et al., 2018). The digitalization of education is controversial and understudied. There are certain limitations to the introduction of $\mathrm{AI}$ in the educational environment related to the teachers not meeting the requirements of the scale of education digitalization and the introduction of AI exhaustively, demonstrating low trust in digital technology, and facing the lack of legal guarantees (Frolova et al., 2019).

Studies on replacing teachers with AI are being conducted. Discussions on the priority of teachers and AI often end in humans' favor. The teacher's personality remains prioritized above $\mathrm{AI}$ in the scientific discourse. As an example, a study compares the abilities of two Confucian teachers: Confucius and a robot Confucius (Tan, 2019). However, the situation might change rapidly and it is crucial to promote the authority of teachers (Poirier et al., 2019; Ilina et al., 2018) and support them (Finkelstein et al., 2014).

The degree to which social networks cover society has an ambiguous effect on people, especially the younger generation and school students (Ahmed et al., 2019). Generation Z proceeds to move away from the previous generations in its development with increasing speed (Howe \& Strauss, 2008). Its development, primarily its social and psychological features, draws the attention of teachers and causes them major concern. The "digital youth" is growing up under the challenging conditions of computerization and facing complex and ambiguous information coming from the media (Schroer, 2020). This generation needs a special approach on the part of 
teachers, as well as social protection from the rapid changes in the social environment (NikiporetsTakigawa, 2018; Frolova et al., 2016; Vinichenko et al., 2019).

Recently, AI started interfering with the existing system of relations between teachers and students. Its participation in this process is evaluated ambiguously and is accompanied by various social and cognitive effects.

\section{Methods}

To identify the nature of the influence digital economy and AI produce on school teachers and students, the Department of Management Sociology of the Faculty of Public Administration of Lomonosov Moscow State University conducted a comprehensive sociological study in February and March of 2020. The study objective was to explore the nature of the influence of the digital economy and AI on the participants of the educational process of the schools in the Krasnodar region, Russia.

\section{Research tasks:}

1. To determine the teacher's status in the teacher-AI system.

2. To identify the nature of AI's influence on communication in the teacher-studentteacher system.

3. To identify the nature of AI's influence on the students.

The following hypothesis was proposed in the study:

H1. The effect of the digital economy and AI on the participants of the process of general school education (teachers and students) has a complex and controversial nature that differentiates the statuses of teachers depending on their sex, age, the experience of working at school, the subject of specialization, and the level of computer literacy.

The study deployed the concept of AI interpreted as intelligent computer programs and systems the purpose of which is to recreate rational reasoning and action. The research involved teachers aged from 27 to 63 years old $(\mathrm{N}=174)$. The general population comprised $\mathrm{N}=35,400$ of teachers from state and municipal organizations of the Krasnodar region. The study involved multistage zoned sampling accounting for the socio-demographic characteristics of the respondents (Table 1). 


\section{Table 1.}

The socio-demographic characteristics of the teachers (in \%)

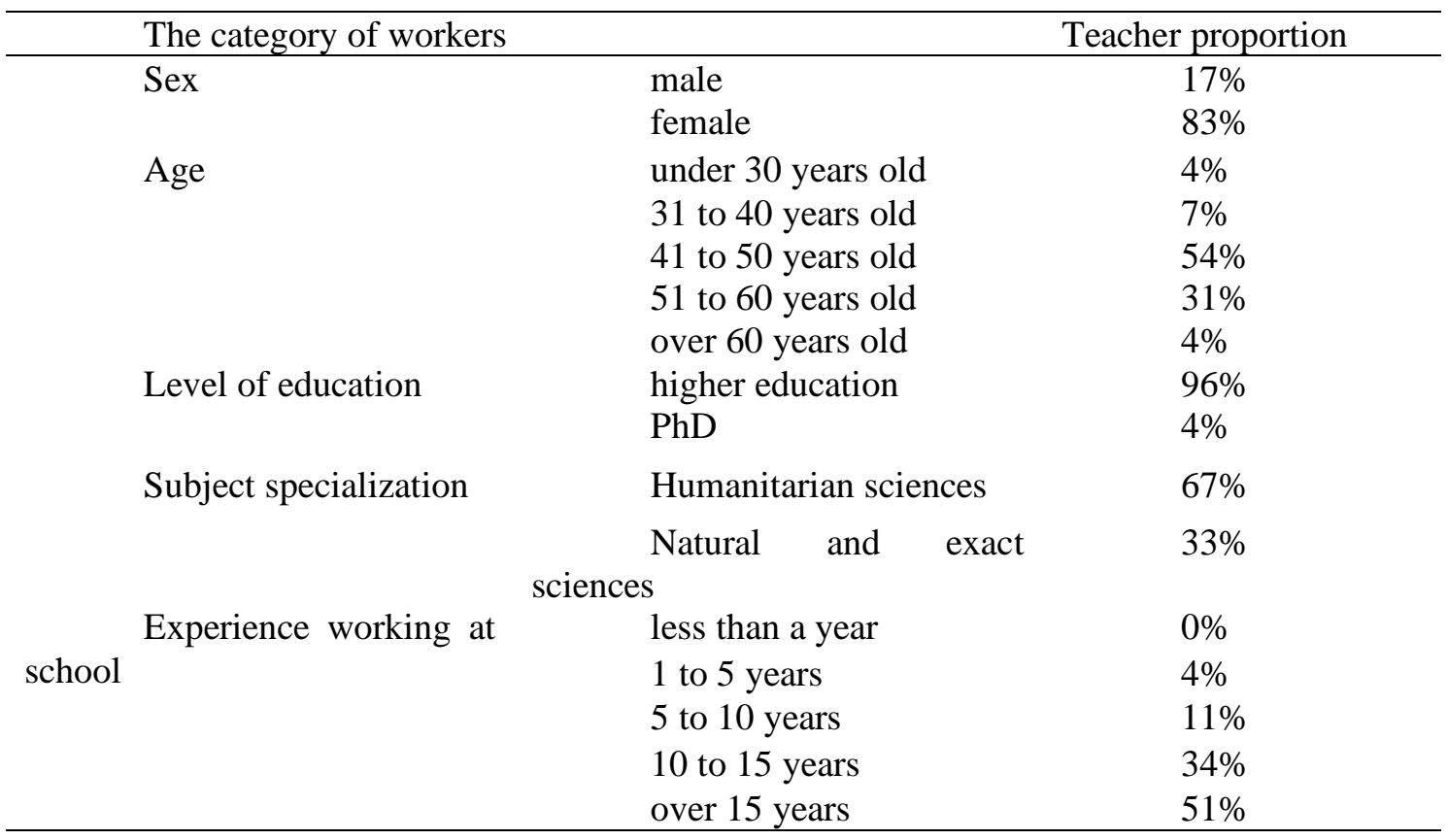

The main sociological data collection and processing methods used in the study included questionnaires, extensive focused interviews, in-depth semi-structured interviews, observation, content analysis, and statistical analysis methods. Likert scale was used in the assessment of the nature of the digital economy and AI's influence on the educational process participants. The acquired data were subjected to comparative analysis. A questionnaire and interviews were conducted in accordance with the ethical requirements for scientific research. Data processing was conducted on a computer via Excel and IBM SPSS Statistics 22. Open questionnaire answers were processed manually followed by data summarization and systematization.

The use of sociological research methods allowed us to discover the preferences of the teachers of various school subjects and identify the specific features of their attitude towards AI in difficult conditions of a pandemic.

\section{Results and discussion}

The status of a teacher in the teacher-AI system

It was established in the course of the study that in the teacher-AI system the respondents gave a much greater preference to the teacher's personality (Figure 1). 


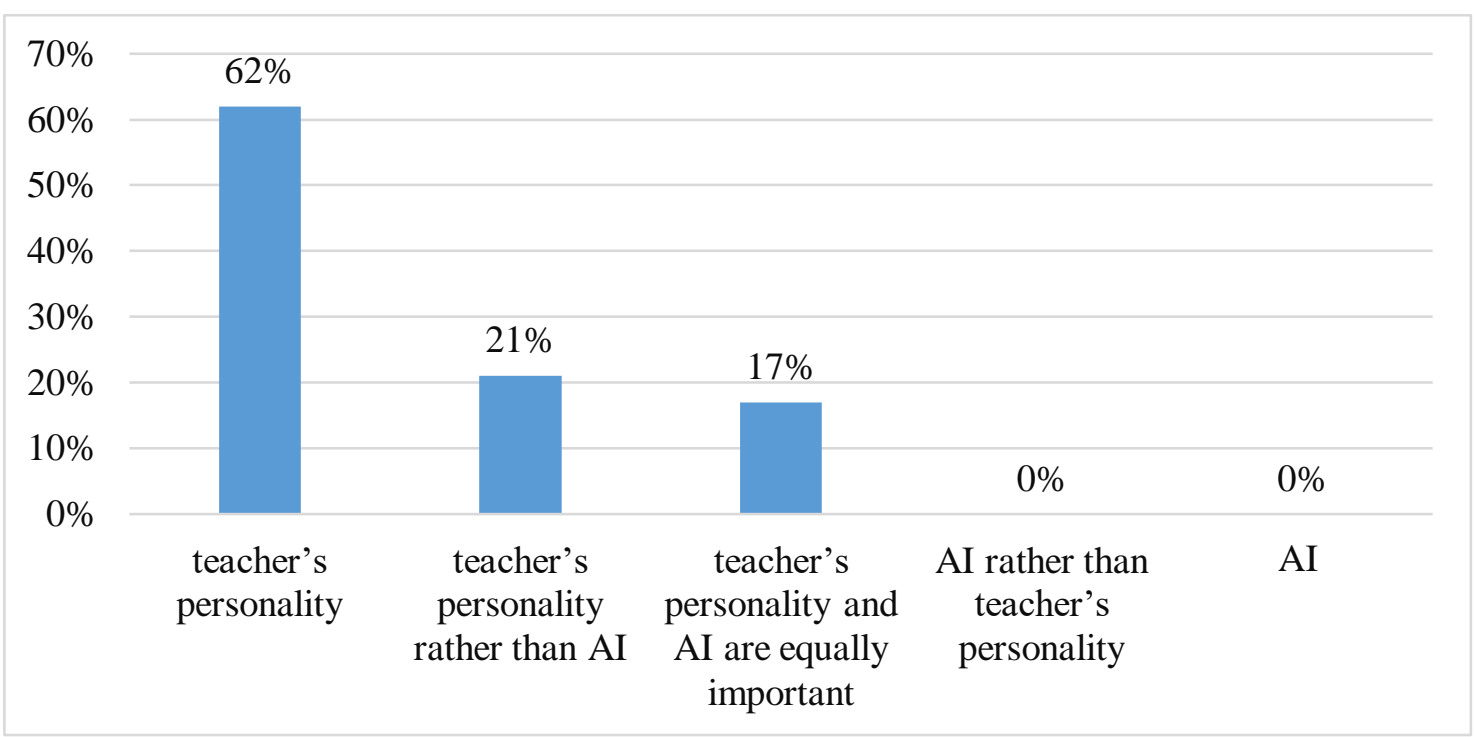

Figure 1. The results of the survey question: "Who (or what) is more important in learning: the teacher's personality or AI?"

A complete conviction with the greater importance of teachers was demonstrated by over half $(62 \%)$ of the respondents. We also discovered a small group of teachers $(17 \%)$ who had already fully implemented AI in their activities and considered the further work of a school teacher to be closely intertwined with the use of AI. This opinion was mostly expressed by teachers under 40 years old with under 10 years of working experience. No proponents of transition towards a secondary role of a teacher in relation to AI was found among the teachers. This finding is natural since it is teachers who are involved in the creation of the pedagogical system and put it into practice during lessons. Like no one else, teachers understand that AI should occupy an assisting function in the education system facilitating the teacher's activities rather than managing or replacing them. Moreover, this question emphasized the personal qualities of a teacher possessing not only natural intelligence but also a soul, social responsibility for the results of their actions, and an understanding that uncontrolled arrays of information do not prepare people for creative work (Matraeva et al., 2020), can alter the landscape of values and meanings, and lead to social and humanitarian degradation and "archaization" of society. These qualities are important for the formation of a new individual worthy of future society. These conclusions are consistent with the results of a study by Charlene Tan (2019) demonstrating the "Digital Confucius" being inferior to a human teacher in the matter of moral education and spiritual development.

This idea is also supported by the results of the survey on whether AI has an advantage over a human teacher (Figure 2). 


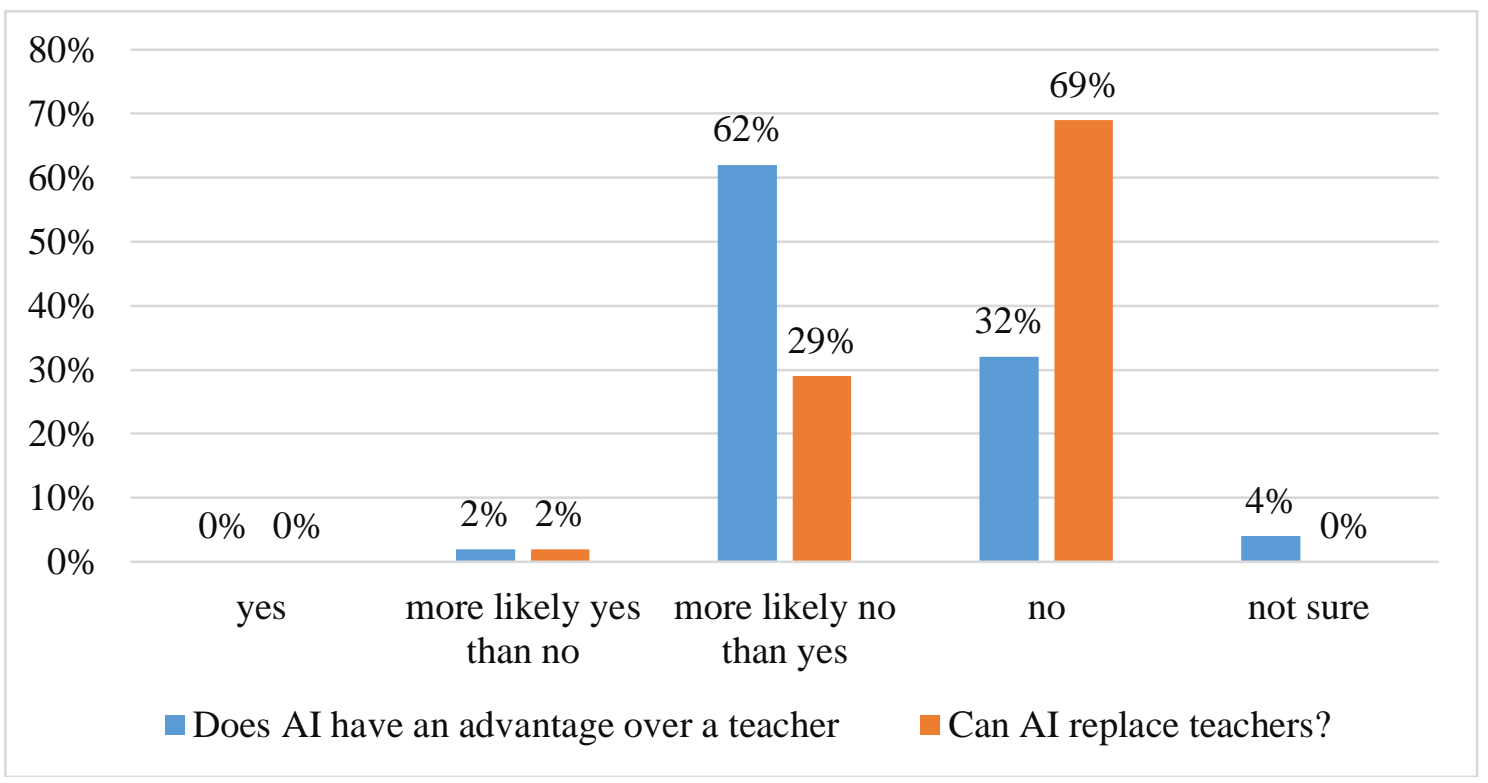

Figure 2. The nature of communication in the teacher-AI system

It should be noted that in this question a teacher was viewed as a specialist in transferring knowledge and the comparison with AI concerned primarily the plane of teaching effectiveness. Nevertheless, a teacher was found to have advantages over AI. Almost all the respondents voted for a human teacher to some extent (94\%). In the present state of technological development, it is still difficult for an inanimate machine to figure out each student's specific characteristics, find a unique approach to them, and choose the method of transmission and the degree of dosing of information in a specific situation. Only a person who has experienced the information and all the problematic issues themselves can ensure the socialization of the young generation and pass the social experience on to it. Nevertheless, $2 \%$ of respondents were inclined in favor of AI giving it an advantage over a teacher and indicating the possibility of AI replacing a teacher. This opinion was expressed by the teachers of natural and exact sciences aged under 30 years old who had under 5 years of working experience. Another significant aspect of this matter is the teacher's communication with the external participants of the teacher-student system - parents and school administration. AI can only perform a retranslating function in this matter. The respondents aged over 40 years old with more than 10 years of experience working at school were among those who completely denied the possibility of AI replacing a teacher.

$69 \%$ of the respondents opposed the idea of replacing a teacher with AI (Figure 2). The majority of the respondents were positive that such measures are inappropriate. However, almost one-third of the respondents demonstrated uncertainty in assessing the possibility of replacing a teacher with an AI. This suggests a steady trend of transferring certain teacher functions to AI present in the pedagogical system. The occurring societal changes cannot leave the educational process unaffected. First, modern children are using electronic devices, the Internet, computer programs, and games from a very young age and are, therefore, unable to determine the role, the scope, and the dangers of economy digitalization and AI themselves. Second, the pedagogical universities are filled with applicants that are far from the best, the quality of teacher training in universities is decreasing, and they do not always have the necessary knowledge and skills necessary for building an appropriate pedagogical system. Third, schools do not create the atmosphere necessary for the adaptation of young teachers, as well as the technology of transferring pedagogical experience from the honored teachers with a great experience. Virtually no representatives of teacher dynasties are found. The above-mentioned factors lead to deviations in the development of teachers and create prerequisites for the emasculation of the pedagogical process and the extrusion of teachers from it promoted by the teachers themselves. 
The rapid introduction of information technology in school education, the requirements of the time and the school administration to switch to the remote form of setting tasks, assigning homework, assessing the quality of preparation and work during lessons, etc., introduces some confusion in determining the role and place of AI in teaching students. Teachers do not have enough time to change their approach and teaching methods accounting for the implementation of AI. It is difficult for children and parents to adapt to distance learning, families often do not have an opportunity to provide their child with a computer and a working space when there are several children on distant learning in the family and parents have to work remotely as well. All the participants of the educational process felt this especially clear during the pandemic. However, the world is changing objectively, and one has to be prepared for it, as is noted in the study by Cornel W. Toit (2019). Students have experienced significant overload during quarantine and self-isolation having to study a greater number of educational materials independently and spend a large amount of time at the computer despite the sanitary standards which harms their health.

Teachers have started working even more since distance learning has transformed into individualized learning with increased bureaucratic procedures. As a result of distance learning teachers have to work 10 to 12 hours per day spending 8 to 10 of them at the computer often without days off. This has a negative influence on their well-being, mental state, and overall health. Parents also find themselves stressed. Some of them could not even imagine the amount of information their children were required to study at school and on their own. This function was performed by teachers and tutors unable to help children in the conditions of quarantine and selfisolation.

Parents who work remotely and perform work functions in a continuous, round-the-clock mode are forced to help their children learn their curricula. Help is not always effective, as not all parents have pedagogical abilities and the necessary knowledge of school subjects. Women often have a harder time, as they still have to maintain the household (Blossfeld \& Huinink, 1991; Padavic et al., 2020). In the context of informational and psychological overload teachers and students need live communication rather than AI. Learning effectiveness is also negatively affected by the lack of a social environment that disciplines students who are at school and under the strict control of the teacher during lessonsa. Students lose interest and motivation to study school material in individual forms and develop laziness.

The nature of AI's influence on communication in the teacher-student-teacher system.

It was established in the course of the study that AI promotes good communication between teachers (Table 2). 64\% of the respondents agreed or rather agreed that AI facilitates communication in teacher-teacher interactions. This proportion included teachers of humanitarian, natural, and precise sciences aged under 50 and having various degrees of working experience. This finding signifies that modern teachers are increasingly more familiar with using the Internet, computer programs, and other services that partially implement AI. 
Table 2.

The results of answers to the question: "Does AI facilitate communication in the various options of teacher-student communication?"

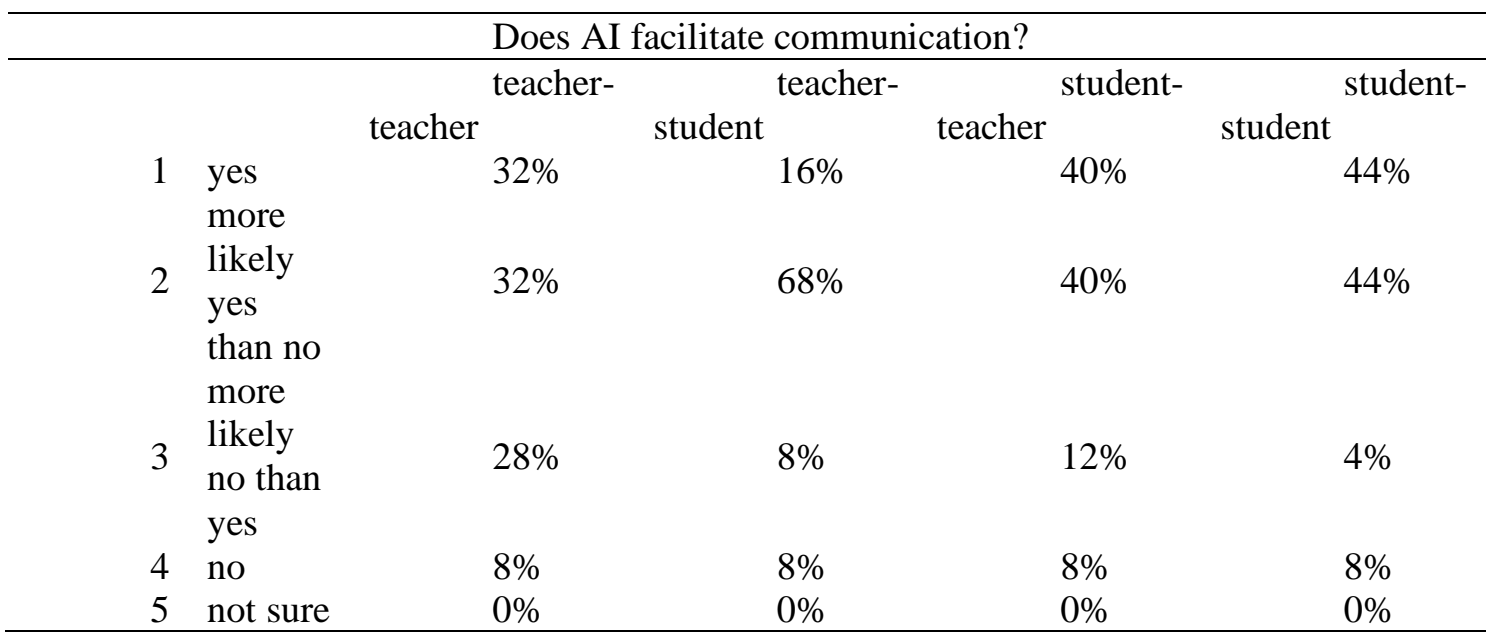

The analysis of data presented in Table 2 illustrates that AI promotes communication between teachers and students. $84 \%$ of the respondents considered this to be a positive effect in the teacher-student system. Moreover, only $16 \%$ of the respondents were completely sure of this. This respondent group was represented by teachers of the natural and exact sciences under 40 years old and with under 10 years of working experience. This result indicates the lack of awareness in teachers, especially the older generation, of the usefulness and importance of using the benefits of $\mathrm{AI}$ in the educational process. The respondents' perception of the communication on the part of the students (student-teacher communication - 80\%) was similar in the number of completely or partially agreeing respondents to the proportion agreeing that AI fosters teacherstudent communication. However, this option had more respondents believing that it is easier for students to establish communication with teachers through electronic devices, the Internet, and computer programs (40\% in student-teacher option against $16 \%$ in the teacher-student option). This finding is quite logical since modern youth uses the achievements of the digitalization of society since childhood. Students' transferring information and supporting communication through various gadgets is the behavioral norm. This corresponds fully to the results of the survey question on the student-student system. The respondents' position on the priority of using the Internet, electronic devices, AI, computer programs, and games for maintaining communication with peers was highly pronounced (88\%). Overall, we should note that there are stable connections in the teacher-student-teacher system that are developed with the support of artificial intelligence.

\section{The nature of AI's influence on students}

The introduction of AI in the life and learning of school students has an ambiguous effect. On the one hand, information technologies and AI help children acquire various information easily and use it in their everyday activities. On the other hand, electronic devices, computer programs, games, and AI overload the student's brain, putting pressure on their psyche and damaging it. The computer environment and games start to replace reality for people leading to the desocialization of children and adults and promoting inadequate behavior.

The analysis of sociological survey data indicated that AI affects students' health negatively (Figure 3). 


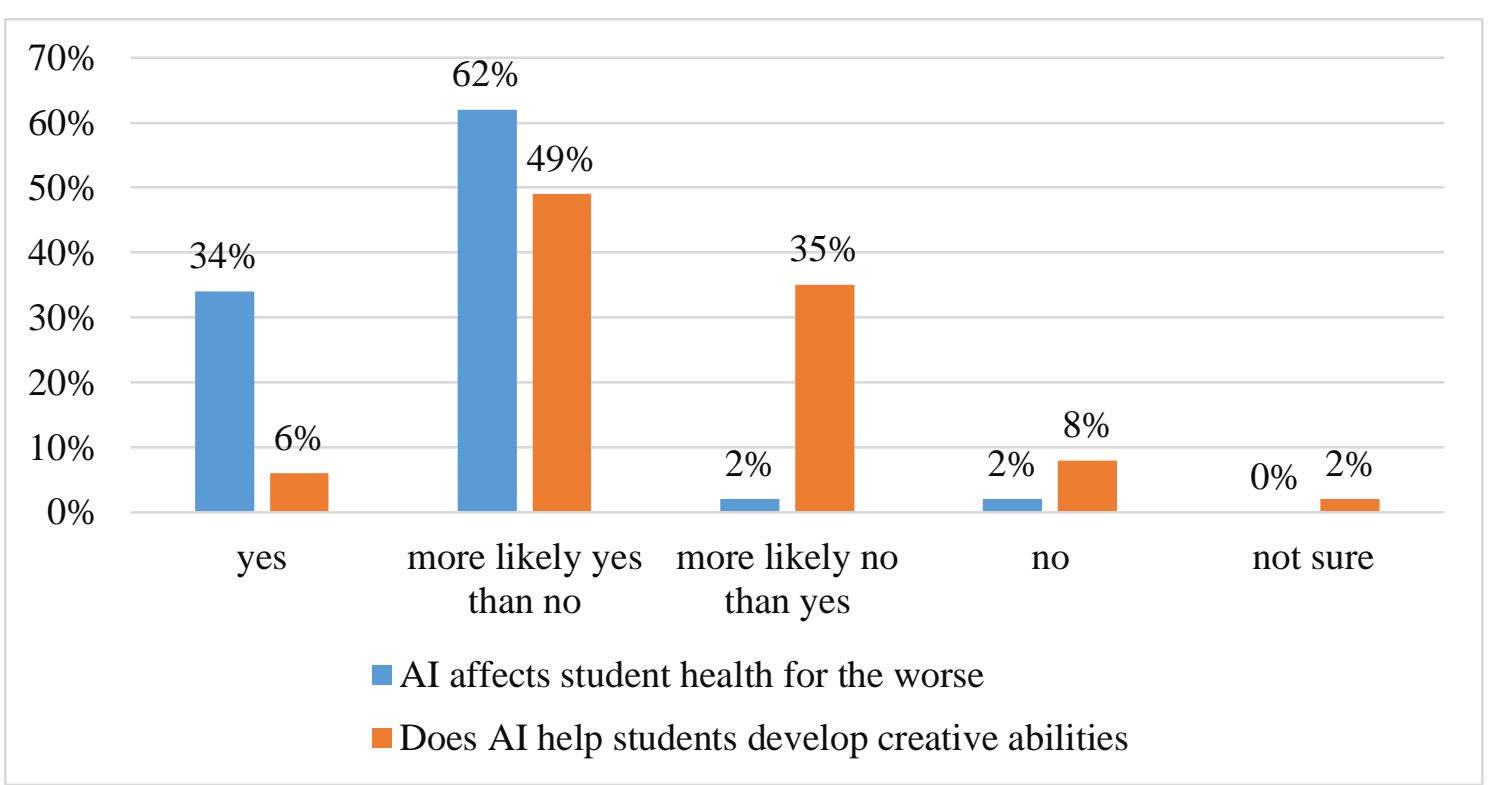

Figure 3. The effect of AI on students

The negative effect of AI on school students' health was noted by almost all of the respondents $(96 \%)$. Teachers attributed this to psychological and emotional overload and high requirements in constantly changing conditions. These conclusions go in line with a study by a collective of researchers (Kalmady et al, 2019) who connected the introduction of AI with the danger of mental health deterioration and schizophrenia.

This manifests in practice in the increased activity of school students during breaks when children become noisy and aggressive in an attempt to express the accumulated internal negative and stressful energy that is being continuously repressed during lessons. The prevention and control of stress-related phenomena become most relevant in such conditions (Isoard-Gautheur et al., 2019).

The noted negative effect of AI also manifests itself in students having difficulty focusing on the topic of the lesson, thinking analytically, and having a discussion with the teacher and other students. The transition to the Unified State Exam reformatted students' way of thinking that is now often aimed at formal memorization of information with the sole goal of answering questions.

As a result, a "competition" with AI through AI itself takes place. Long periods spent by the students at computers and other electronic devices have an adverse effect on vision, psychological state, the development of imaginative thinking, speech, the musculoskeletal system of a child, and the overall formation of a person, especially in the conditions of self-isolation due to the pandemic. School students sit at their computers for 8 to 10 hours or more attending remote classes, doing homework, chatting with friends, and scrolling through social networks. This leads to a decrease in students' immunity and diseases that are especially dangerous during a pandemic.

Along with this, $2 \%$ of the respondents expressed the opinion that AI does not adversely affect the health of students. This position was taken by teachers under 30 years old specializing in natural and precise sciences who had under 5 years of working experience. Their young age, previously acquired traditional education, lack of experience, and enthusiasm related to their subjects had not yet had a significant impact on their health and they tended to believe that the health of school students cannot be threatened by AI either.

The respondents provided interesting answers to the question of the role of $\mathrm{AI}$ in the development of students' creative abilities. Half of the respondents believed that AI facilitates the development of school students' creative potential. However, creativity in its classical 
understanding is only inherent to humans and can be developed either on one's own or with the help of others - parents, teachers, or specialists in the development of human potential in the creative social environment, which is supported by some studies (Matraeva et al., 2020).

The experience of recent years demonstrates that information technology and AI assist in revealing human potential more fully. The more active and progressive teachers search for the ways of implementing computer programs, games, the Internet, and the elements of AI in teaching school students and developing their human competences, creative abilities included. In the present study, this tendency was demonstrated by the teachers of humanitarian, natural, and exact sciences aged under 50 years old who had under 15 years of working experience. In this regard, it is important to combine the rich experience of using traditional means of education with advanced information technologies and develop the motivation for high-quality pedagogical work (Poirier et al., 2019).

These alterations are especially vital in the conditions of the digitalization of society. School students interact with electronic devices since early childhood and are ready for active communication with the outside world and teachers at school via information technology and electronic devices. In this regard, teachers see AI both as an assistant and a threat. AI manifests as an assistant in work with the typical representatives of the digital generation, Generation Z. These representatives are interested in the most recent achievements of science and technology and strive to expand their knowledge, sometimes only in certain selected areas, saving their resources. Despite their parents working remotely sometimes, school students do not always receive enough attention and assistance in their development. A portion of education and upbringing functions is transferred to tutors.

School students still lack a stable value system and a clearly constructed system of knowledge acquisition. There is, therefore, a danger of them developing laziness in studying various subjects due to relying on the capabilities of AI. This results in the simplification and underdevelopment of thinking of the entire generation rather than individual students. From this point, the digital generation, Generation Z, is under a certain threat (Howe \& Strauss, 2008). A danger of students receiving misinformation from various sources, primarily the Internet, social networks, and the media, is also present. These conclusions go in line with a study by Andrea Zanotti (2018) indicating that the media and the Internet present an environment favorable for saturating the society with fake news. The lack of systemic thinking will prevent school students from sorting the information and identifying falsifications. This issue heavily concerns the teachers of Generation $\mathrm{Y}$ who still possess the ability for systemic analysis and obtaining knowledge from trusted paper-based sources. Electronic resources are more vulnerable and depend on electricity, the quality of electronic devices, networks, possible electronic attacks, and system failures.

\section{Conclusion}

It was found that the vast majority of the respondents gave their preference to the personality of a teacher in the teacher-AI system. There was also a smaller portion of teachers under 40 years old with under 10 years of working experience who had already implemented AI in their activities to the fullest extent and believed that the teacher's role in relation to AI would change in the future. The teacher's advantage over AI in the technique of teaching school students was also identified along with the impossibility of replacing a teacher with an AI. Furthermore, a part of the respondents expressed some uncertainty in their assessment of the possibility of replacing a teacher with an $\mathrm{AI}$ and $2 \%$ of the respondents were more inclined towards AI attributing advantage over a teacher to it and considering AI replacing teachers as a possible alternative. This respondent group included teachers of natural and precise sciences aged under 30 years old and having under 5 years of working experience. There is an increasing danger of the emasculation 
of the pedagogical process and the extrusion of teachers from it promoted by the teachers themselves. This possibility is especially dangerous in the conditions of the pandemic.

It was established that AI promotes the formation of stable connections in the teacherstudent-teacher system. The most effective way of communication in the teacher-student system and between the students was identified.

The effect of AI on the life and study of school students was found to be ambiguous. Information technologies and AI both promote obtaining various information and bring pleasure from computer games and communication with peers and adults and cause damage to children overloading their brain, adversely affecting the psyche and damaging it. The computer environment and games start to replace reality for people promoting inadequate behavior.

The overwhelming majority of the respondents were positive that AI affects student health negatively. Their opinion was based on pedagogical and personal experience and related to psychological and information overload and high requirements in a constantly changing environment. This becomes increasingly relevant in the context of restrictions introduced due to the ongoing pandemic. Remote studying and communication with peers continuing for 8-10 hours or more per day have a negative impact on school students' health, vision, and immune system.

Overall, the initial hypothesis was confirmed - the influence of digital economy and AI on the school educational process participants (teachers and students) was found to have a complex and controversial nature that differentiates the statuses of teachers depending on their age, working experience, and the subject of specialization. This issue has to be the focus of increased attention of the national government and the highest authorities of the educational sphere, heads of the educational organizations, teachers, and parents. Not only the way of the humanitarian development of society but also the future of their children depends on their position and participation regarding this topic.

\section{References}

Abassi, L., Boukhris, I. (2018). Imprecise Label Aggregation Approach Under the Belief Function Theory. Advances in Intelligent Systems and Computing, 941, 607-616.

Abubakar, A.M., Behravesh, E., Rezapouraghdam, H., Yildiz, S.B. (2019). Applying artificial intelligence technique to predict knowledge hiding behavior. International Journal of Information Management, 49, 45-57.

Ahmed, Y.A., Ahmad, M.N., Ahmad, N., Zakaria, N.H. (2019). Social media for knowledgesharing: A systematic literature review. Telematics and Informatics, 37, 72-112.

Alzoubi, I., Almaliki, S., Mirzaei, F. (2019). Prediction of environmental indicators in land leveling using artificial intelligence techniques. Chemical and Biological Technologies in Agriculture, 6(1).

Blossfeld, H.P., Huinink, J. (1991). Human Capital Investments or Norms of Role Transition? How Women's Schooling and Career Affect the Process of Family Formation. American Journal of Sociology, 97(1).

Burrell, L. (2019). Artificial intelligence brings out the worst and the best in us. MIT Sloan Management Review, 60(2).

Cha, Y.J., Baek, S., Ahn, G., Lee, H., Lee, B., Shin, J. (2020). Compensating for the loss of human distinctiveness: The use of social creativity under Human-Machine comparisons. Computers in Human Behavior, 103, 80-90.

Das, S., Sanyal, M.K., Datta, D. (2019). Artificial intelligent reliable doctor (AIRDr.): Prospect of disease prediction using reliability. Studies in Computational Intelligence, 784, 21-42.

Effron, M., Orth, M. (2014). Talent Management - a short course: Azbuka Biznesa, 224.

Finkelstein, M., Iglesias, K., Panova, A.A., Yudkevich, M. (2014). Prospects for young professionals in the academic labor market: global comparison and assessment. Educational issues, 2, 20-43. 
Frolova, E.V., Medvedeva, N.V., Kabanova, E.E., Kurbakova, S.N., Vinichenko, M.V. (2016). Social Partnership in Russia: Prerequisites, Problems and Trends. Journal of Advanced Research in Law and Economics, 2(16): 221-228.

Frolova, E.V., Ryabova, T.M., Rogach, O.V. (2019). Digital technologies in education: problems and prospects for "Moscow electronic school" project implementation. European Journal of Contemporary Education, 8(4), 779-789.

Fujimura, K. (2019). Constructing a Work Motivation Model Based on "Benefit Delay" and "Benefit Enjoyment". In book: Advances in Human Factors, Business Management and Leadership, pp. 251-262.

Howe, N., Strauss, W. (2008). Millennials \& K-12 Schools. Great Falls: LifeCourse Associates.

Ilina, I.Y., Oseev, A.A., Vinichenko, M.V., Kirillov, A.V., Kaurova, O.V., Nakhratova, E.E. (2018). Transformation of Social Status Of Teachers Of Russian Universities. Modern Journal of Language Teaching Methods, 8(3), 381-392.

Isoard-Gautheur, S., Ginoux, C., Gerber, M., Sarrazin, P. (2019). The Stress-Burnout Relationship: Examining the Moderating Effect of Physical Activity and Intrinsic Motivation for Off-Job Physical Activity. Workplace Health and Safety, 67(7): 350-367.

Jackson, Barry L. (2019). Future Shock Revisited. Postmodern Openings, 10(3): 102-116.

Kalmady, S.V., Greiner, R., Agrawal, R., Shivakumar, V., Narayanaswamy, J.C., Brown, M.R.G., Greenshaw, A.J., Dursun, S.M., Venkatasubramanian, G. (2019). Towards artificial intelligence in mental health by improving schizophrenia prediction with multiple brain parcellation ensemble-learning. npj Schizophrenia, 5(2).

Kamal, E., Adouane, L. (2019). Reliable energy management optimization in consideration of battery deterioration for plug-in intelligent hybrid vehicle. Lecture Notes in Electrical Engineering, 495, 150-17314.

Kamimura, R., Takeuchi, H. (2019). Intelligent Systems and Applications. Excessive, Selective and Collective Information Processing to Improve and Interpret Multi-layered Neural Networks: Proceedings of the 2018 Intelligent Systems Conference (IntelliSys) Volume 1. In book: Intelligent Systems and Applications, pp. 664-675.

Koch, K.-R., Brockmann, J.M., (2019). Artificial intelligence for determining systematic effects of laser scanners. GEM - International Journal on Geomathematics, 10(1).

Kumar, V., Kumar, A. (2019). Studying the behavior of neural models under hybrid and reinforced foundations. Innovative Infrastructure Solutions, 4(1).

Kurita, Y., Kuwahara, T., Hara, K., Mizuno, N., Okuno, N., Matsumoto, S., Obata, M., Koda, H., Tajika, M., Shimizu, Y., Nakajima, A., Kubota, K., Niwa, Y. (2019). Diagnostic ability of artificial intelligence using deep learning analysis of cyst fluid in differentiating malignant from benign pancreatic cystic lesions. Scientific Reports, open access, 9(1).

Lee, C.S, Tyring, A.J., Wu, Y., Xiao, S., Rokem, A.S., DeRuyter, N.P., Zhang, Q., Tufail, A., Wang, R.K., Lee, A.Y. (2019). Generating retinal flow maps from structural optical coherence tomography with artificial intelligence. Scientific Reports, 9(1).

Manita, R., Elommal, N., Baudier, P., Hikkerova, L. (2020). The digital transformation of external audit and its impact on corporate governance. Technological Forecasting and Social Change, $150(\mathrm{C})$.

Matraeva, A.D., Rybakova, M.V., Vinichenko, M.V., Oseev, A.A., Ljapunova, N.V. (2020). Development of Creativity of Students in Higher Educational Institutions: Assessment of Students and Experts. Universal Journal of Educational Research, 8(1), 8-16.

Moskaleva, N.B., Zaitseva, N.A., Vinogradova, M.V. (2018). The Use Of Digital Technologies To Improve The Quality Of The "Social Taxi" Services'. Modern Journal Of Language Teaching Methods, 8(5), 43-55.

Natale, Simone, Ballatore, Andrea. (2020). Imagining the thinking machine: Technological myths and the rise of artificial intelligence. Convergence-The International Journal Of Research Into New Media Technologies, 26(1), 3-18.

Nikiporets-Takigawa, G. (2018). Youth and youth policy in the UK: Post-brexit view. Sovremennaya Evropa, 1(80), 47-58. 
Ossmy, O., Gilmore, R.O., Adolph, K.E. (2019). AutoViDev: A Computer-Vision Framework to Enhance and Accelerate Research in Human Development. Advances in Intelligent Systems and Computing, 944, 147-156.

Padavic, I., Ely, R.J., Reid, E.M. (2020). Explaining the Persistence of Gender Inequality: The Work-family Narrative as a Social Defense against the 24/7 Work Culture. Administrative Science Quarterly, 65(1), 61-111.

Poirier, T.I., Fryman, K., Newman, K., Studnicki, K. (2019). PharmD graduates' perceptions of the impact of a teaching specialization. Currents in Pharmacy Teaching and Learning, 11(7), 678-689.

Pomato. (2020). AI for hiring. Make the right hire. Right now. Retrieved from: https://www.pomato.com/

Rogach, O.V., Frolova, E. V., Ryabova, T. M. (2018). Theory of "trust" in the focus of expectation study concerning educational space key actors. Journal of Contemporary Education, 7(2), 392-399.

Rogach, O.V., Frolova, E.V., Kirillov, A.V., Bondaletov, V.V., Vinichenko, M.V. (2016). Development of favorable learning environment and labor protection in the context of harmonization of social interaction of education system objects. IEJME - Mathematics Education, 11(7): 2547-2558.

Sears, D. (2003). Successful talent strategies: achieving superior business results through marketfocused staffing. New York: American Management Association.

Shakhovska, N., Vovk, O., Holoshchuk, R., Hasko, R. (2020). The Student Training System Based on the Approaches of Gamification. Advances in Intelligent Systems and Computing. 2nd International Conference on Computer Science, Engineering and Education Applications, ICCSEEA, 938, 579-589.

Shi, Y. (2019). The Impact of Artificial Intelligence on the Accounting Industry. International Conference on Cyber Security Intelligence and Analytics. Advances in Intelligent Systems and Computing, 928, 971-978.

Smilansky, J. (2005). The Systematic Management of Executive Talent. Hydrogen, 65(1), 61111.

Sukhorukov, A.I., Shuhong, G., Koryagin N.D., Eroshkin, S. Y. (2018). Tendencies of Information Management Development in the Conditions of the Origin of a New Ecosystem of the Digital Economy. Moscow: 2018 Eleventh International Conference "Management of large-scale system development" (MLSD).

Tan, C. (2019). Digital Confucius? Exploring the implications of artificial intelligence in spiritual education. Connection Science. DOI: 10.1080/09540091.2019.1709045

Thunnissen, M. (2016). Talent management: for what, how and how well? An empirical exploration of talent management in practice. Employee Relations, 38(1): 57-72.

Toit, C.W. (2019). Artificial inelligence and the question of being. HTS Teologiese StudiesTheological Studies, 75(1), 1-10.

Tong, Z., Chen, H., Deng, X., Li, K., Li, K. (2020). A scheduling scheme in the cloud computing environment using deep Q-learning. Information Sciences, 512, 1170-1191.

Vergara, D., Rubio, M.P., Lorenzo, M., Rodríguez, S. (2020). On the importance of the design of virtual reality learning environments, Advances in Intelligent Systems and Computing, 1007: 146-152. 9th International Conference in Methodologies and Intelligent Systems for Technology Enhanced Learning.

Vinichenko, M.V., Karácsony, P., Demchenko, T.S., Ilina, I.Y., Makuchkin, S.A. (2017). Improvement of youth personnel policy: Social inspection. Eurasian Journal of Analytical Chemistry, 12(7b), 1069-1077.

Vinichenko, M.V., Klementyev, D.S., Rybakova, M.V., Malyshev, M.A., Bondaletova, N.F., Chizhankova I.V. (2019). Improving the efficiency of the negotiation process in the social partnership system. Entrepreneurship and sustainability issues, 7(1), 92-104.

Zanotti, A. (2018). Post-truth as the face of a new inquisition. AIB STUDI, 58(3), 439-453.

Zhang, Q., Yu, H., Barbiero, M., Wang, B., Gu, M. (2019). Artificial neural networks enabled by nanophotonics. Light: Science and Applications, 8(1). 
Zimenkova, A.A., Paramonova, T.A., Lobacheva, A.S. (2018). The problem of the introduction of artificial intelligence in HR. In the collection: Step into the Future: Artificial Intelligence and the Digital Economy. Management revolution: New digital economy or new world of machines. Materials of the II International Scientific Forum, 292-297. 